\title{
Factors Affecting Learning Gains among Students in Microbiology Class: A Preliminary Study Between a U.S. Community College and a Canadian Comprehensive University
}

Nacwarat Cheeptham and Archana Lal

Noawarat Cheeptham*

Department of Biological Sciences

Thompson Rivers University

Kamloops, B.C., Canada

Archana Lal

Labette Community College

Pittsburg, KS

${ }^{*}$ Corresponding author, Ncheeptham@tru.ca

Manuscript received 17 June 2019; accepted 28 January 2020.

12 | Fine Focus 


\section{Abstract}

Though in the past, serious concerns have been raised about students' interest and learning gains in STEM courses, not much research has been done to examine the differences in learning science at community colleges and universities. The purpose of this paper is to close this gap. This paper analyzes the influence of students' demographics, preparedness, major, and attitudes on their learning gains in an introductory microbiology class at a community college vs. a university. Student demographics, information about their preparedness level, major, and attitudes were collected in a questionnaire and students' learning gains were assessed by comparing student performance on a pre- and post-test on four different topics in microbiology. Our results indicate that students' majors and attitudes such as their willingness to actively participate in the classroom discussions and spend time outside the classroom to learn are major factors that enhance their learning. Age and marital status positively impact learning gains while gender, employment status, and citizenship status show no impact on learning gains in students. Our results also indicate that students at the community college who had less exposure to science classes in high school or biology classes in college achieved statistically higher learning gains despite having overall lower scores on two of the four post-tests.

\section{Introduction}

Volume Six | 13 
In recent years, there has been a growing need for students trained in the fields of science, technology, engineering, and mathematics (STEM) in the U.S., while an increased interest in STEM education has steadily been recognized in Canada. STEM's crisis is not as obvious in Canada, however, STEM-related career and job preparedness is more prominent. The Canadian Government has created and put forward many STEM initiatives and educational programs to prepare Canadians for STEM-related careers and jobs (1). Canadian STEM graduates continue to demonstrate disparities between gender and minority representation (2). In the 2011 National Household Survey (NHS), it was found that only $18.6 \%$ of adults with a postsecondary certificate, diploma, or degree are qualified in STEM fields of study. Of those, among younger STEM graduates, women held a higher share of university degrees, while men still held the majority of university STEM degrees in older demographics. It seems that overall Canada is better prepared for STEMrelated careers and jobs than the U.S. $(3,4)$. Blotnicky et al. demonstrated that overall Atlantic Canada middle school students $\left(7^{\text {th }}\right.$ to $9^{\text {th }}$ graders $)$ from public schools lacked knowledge about STEM career requirements and their findings support the need to create better accessibility of knowledge pertaining to STEM career requirement to facilitate students' understanding of the nature of a STEM career (5). At McGill University, Montreal, Quebec on November 28, 2015 the Canadian Science \& Policy Exchange convened a working group composed of STEM students and experts representing the perspectives of academic, government, and private sectors to discuss current challenges and opportunities in Canadian STEM Education (6). Canadian STEM students voiced many challenging issues in regard to the current delivery of their STEM education. These challenges include issues in, one, Curriculum and structure (large class size, lack of applied learning), two, Critical skills development, three, Career exposure, and, four, Metrics and evaluation. After working with experts during the working groups, several solutions to these issues were recommended from the students. The first four solutions at the top of the list were, one, reducing class sizes to improve student engagement, two, developing interdisciplinary courses to expose STEM students to diverse perspectives for problemsolving, three, increasing direct training in the critical skills that employers expect from STEM students, and, four, fostering an early awareness of STEM careers and encouraging students to be proactive in forming a career plan (6). However, there is less research published on STEM education related topics in Canada in relation to the U.S.

Though the number of students pursuing their education in STEM fields in the U.S. has increased, it has not been enough to meet the increasing demands in STEM (7). There has been a shortage of workers and students proficient in math and science (8). The National Math and Science Initiative (NMSI) (http:// www.nms.org/) states that the United States is losing its competitive edge in STEM areas (9) and this shortage is appropriately called “The STEM Crisis”. In 2012, the President's Council of Advisors on Science and Technology (PCAST) issued a report suggesting an increase in the number of STEM graduates in the next decade to meet projected employment needs (8).

A major reason for "The STEM Crisis" in the U.S. has been a declining trend in the adequate preparation of 
high school students to be successful in college level courses. According to an NMSI estimate (9), in 2009, only $21 \%$ of $12^{\text {th }}$ grade students performed at or above proficient level in science; in the high school class of 2012, of all the students who took an Advanced Placement test, only $19.5 \%$ earned a qualifying score; and only $13 \%$ of high school graduates in 2013 were ready for college level science. In 2012, U.S. students were ranked $27^{\text {th }}$ in Math and $20^{\text {th }}$ in Science while China, Korea, Japan, and Canada were all ahead of the U.S. Recognizing the STEM crisis, in December 2018, the U.S. federal government has adopted a detailed strategy to make the U.S. a global leader in STEM literacy, innovation, and employment by pursuing three objectives; one, build a strong foundation for STEM literacy, two, increase diversity, equity, and inclusion in STEM, and, three, prepare the STEM workforce for the future (10).

Given the seriousness of issues surrounding science education, it is not surprising that several studies have examined the factors that influence post-secondary students' interest and desire to pursue careers in STEM fields. Astin and Astin (1992), for example, reported a significant positive correlation between institutional traits and background characteristics of students and their interest in studying science and related fields during their post-secondary studies (11). They stated that the level of mathematical preparation in high school is the strongest and most consistent predictor of students' initial interest as well as continuation of their education in STEM fields.

Several studies have examined the impact of background characteristics such as age (12), gender $(13,14)$, marital status (12), family income (12), academic success (13), financial situation (15), and previous educational experiences (11) on retention of STEM majors into and during post-secondary education. Leppel found that age, marriage, and hours employed have a negative impact on college persistence while family income and GPA have a positive impact on both men's and women's persistence (12). Similarly, Cabrera and La Nasa showed that factors like family income, parental education, gender, ethnicity, and exposure to at-risk factors in lowest socio-economic status place students at a disadvantage and make their path to college extremely difficult (13). Whalen and Shelley showed that underrepresented (female and/or minority) students do not perform as well in STEM majors as traditional white, male students (14).

Academic performance of students has always been a topic of interest, discussion, and research among educators in many disciplines. Much of the earlier research analyzed the relationship between students' demographics, experiences in high school, their entry qualifications, type of institutions and their performance in college classes. Effects of many different demographic factors on student learning in different fields have been examined, for example, age $(16,17,18$, $19,20,21)$, gender $(17,19,20,22,23,24)$, race (24), employment status $(13,17)$, and citizenship $(17,18)$. In studies where the effects of age and gender on academic performance were examined, mixed results have been reported. In an introductory biochemistry class, Mlambo reported that gender and age did not cause any significant variation in the academic performance (19). Similarly, in a study by Colorado and Eberle, age was 
not a significant factor affecting academic performance of graduate students enrolled in online classes (16). Jayanthi et al. also reported no significant impact of age on academic performance of post-secondary students (17). Newman-Ford et al. reported minor impact of age and gender on educational achievements in first year undergraduates (20). In a study by Richardson and King (1998), older students exhibited more desirable approaches to learning in terms of their persistence and attainment (21). In some studies, no link was found between gender or race (except for Latinos) and student performance in an introductory college chemistry class (24) and mathematics class (23). In contrast, in other studies, female students were found to outperform male students $(17,22)$. Few studies reported a correlation between nationality and student performance. A study done in Singapore reported that international students performed better than domestic students (17).

In addition to age, gender, race, and nationality, other factors that influence student achievement in postsecondary education have also been researched. It is widely accepted that well prepared students are more likely to pursue their initial choice of a science major. Astin and Astin (1992) suggested that it may be possible for more students to pursue science majors and careers if the level of overall academic competency could be increased at the secondary level (11). Newman-Ford et al. reported a significant impact of prior educational attainment, and attendance on educational achievement of first year undergraduate students in U.K (20). Along the same lines, Jayanthi et al. reported that intention to pursue higher studies and learning preferences contribute to students' academic performance significantly (17). On the contrary, 伯 | Fine Focus in a study in an introductory biochemistry class, it was concluded that learning preferences and entry qualifications do not cause any significant variation in the academic performance of students (19).

It is well known that students who have no visible or significant gaps or barriers in learning in high school are better prepared to handle the rigor of college. Tai et al. reported a significant correlation between pedagogical experiences of students during high school class and their performance in introductory college chemistry class (24). They also concluded that demographic predictors like parents' educational level, family income, and affluence of the community were linked to significant differences in how students perform in their college class.

Despite the complexity and the importance of issues relating to student learning in STEM fields, we found very few studies that compared learning gains between two- and four-year educational institutions. The purpose of this paper is to fill this gap. Thus, this paper examined learning gains of students enrolled in an introductory microbiology class at a two-year college in the U.S. and at a four-year university in Canada. This paper compared the student composition (in terms of demographics, level of preparation, major, and attitudes) at the two educational institutions by means of a questionnaire administered at the beginning of the semester. We also analyzed the results of the same pre- and post-tests (details are provided in the methods section) taken by students at both the institutions to test whether their learning gains are linked to the nature of institutions, students' prior exposure to 
the subject matter, attitudes towards microbiology, and demographics. Further, we have provided several plausible explanations consistent with our findings of differences in students' learning at two types of institutions.

\section{Methods}

This study was conducted at a U.S. Community College (USCC) and a Canadian University (CU). The microbiology class at USCC was capped at 20 students and there was a mix of traditional ( 25 or younger) and non-traditional students (above 25 years of age) (72\% vs $28 \%$ ) and the majority of them were pre-nursing majors (88\%). At CU, most students were traditional students (98\%), majoring in biology/microbiology/ pre-med (67\%) and the class size was capped at 80 (one big lecture class divided into 5 lab sections with a maximum of 16 students in each lab section). The lab sections met for microbiology experiments (once a week at CU and twice a week at USCC) for a total of 170 minutes per week. At both the institutions, students worked in a group of 2-4 students during each lab period. Though microbiology is a sophomore level class at both the institutions, at USCC it has no prerequisite and almost all the pre-nursing students take it during their freshman year. In contrast, at $\mathrm{CU}$, first year biology and chemistry are the prerequisites to take microbiology, and hence all the students enrolled in microbiology are sophomores. At both the institutions, the traditional lecture discussion format was used in the classroom (lecture followed by discussions from student questions). Despite the differences in class sizes and prerequisites, both the instructors had similar expectations from their students in terms of learning.
Both the courses had the same learning objectives and students at both the institutions were given the same pre- and post-tests. To minimize differences in teaching styles and content, both instructors communicated on a weekly basis to discuss the lesson plans and the mode of delivery.

At the beginning of the semester, the purpose as well as the details of this research study were explained to the students. Although, the participation in this study was voluntary and students were asked to sign a consent form, all the students present on day 1 of the semester, chose to participate. Students were also explained that their identities would remain anonymous, the information they provided would always remain confidential, and their names would never be released in any form in the study. The data were not analyzed until after the semester was over and the students' names or identities were not shared between the two instructors (authors of this paper). An IRB approval was obtained at $\mathrm{CU}$ before the beginning of the study whereas no IRB approval was required at USCC.

A questionnaire and a test for each of the four selected topics in microbiology were developed (supplemental materials available upon request). The questionnaire consisted of fifteen questions and was administered at the beginning of the semester to collect information on: (a) the demographics of each student, i.e., age, gender, marital status, number of hours working per week, and citizenship status; (b) student preparedness, i.e., number of science courses they completed in high school, other biology courses completed in college before enrolling in microbiology, and their major; (c) 
students' interest in microbiology and their attitudes, study habits, and behavioral engagement towards learning, i.e., their willingness to actively participate in the classroom, their attitude towards the laboratory participation, and their willingness to spend time learning outside the classroom. All the questions in the tests, administered before (pre-test) and after (posttest) class room discussion, were either selected from the test bank of the microbiology text books (difficulty level 1) or written by the authors at the lower levels of Bloom's taxonomy (knowledge and comprehension). Each question was carefully selected to assess students' basic knowledge and understanding in the following topics:

- Introduction to microbiology

- Cell structure

- Microbial metabolism

- Microbial growth

We assessed the prior knowledge of basic concepts of students enrolled in microbiology class by administering a test before the topic was discussed in class. After the topic was discussed, we administered the same test as a post-test to determine their learning gains by comparing each student's score on post-test to their score on pre-test. Students were not told that they would be taking an identical test for both pre-test and post-test. Each test comprised of a total of 10 questions worth 1 point each, for a maximum of 10 points. The data were collected from both the institutions for statistical analyses after the semester was over. We compared the demographics of students enrolled in the microbiology class at USCC and CU and related them to student learning gains on the post-test versus 18 | Fine Focus the pre-test.

Students' responses to different questions on the questionnaire were statistically analyzed and the results are presented in Fig. 1. To statistically analyze the differences in student demographics and their preparedness, a binary classification was used

(Table 1).

The data for students' attitudes were collected on a 5-point Likert scale, where 1 represents the least value and 5 represents the highest value (for example, regarding interest in microbiology, 1 represents no interest and 5 represents high interest).

To analyze differences between variables, a test of equality of means was used. We have used $94 \%$ level of confidence to accept or reject the null hypothesis. Thus, $\boldsymbol{p}$-values, based on $\boldsymbol{t}$-tests, of less than or equal to $0.06(6 \%)$ rejects the null hypothesis of equality of means between variables. EVIEWS software was used for statistical analysis.

\section{Results}

At the beginning of the semester, on the first day of classes, a questionnaire was administered to collect the basic information of students enrolled in microbiology class at both the institutions. Fig. 1 (A), (B), and (C) summarize the differences between USCC and CU students based on their responses to our questionnaire. Fifteen students at USCC and 70 students at CU completed and submitted the questionnaire. Based on the analysis of our data, Fig. 1 (A) shows that CU had 


\begin{tabular}{llc}
\hline Age & Below 25 years & 1 \\
\cline { 2 - 3 } & Otherwise & 0 \\
\hline \multirow{2}{*}{ Gender } & Male & 1 \\
\cline { 2 - 3 } & & 0 \\
\hline \multirow{2}{*}{ Marital status } & Otherwise & 1 \\
\cline { 2 - 3 } & & 0
\end{tabular}

More than 10 hours per week 1

Employment status

Otherwise 0

\begin{tabular}{|c|c|c|}
\hline \multirow[t]{2}{*}{ Citizenship } & $\begin{array}{l}\text { Domestic citizen (USA at } \\
\text { USCC \& Canadian at CU) }\end{array}$ & 1 \\
\hline & Otherwise & 0 \\
\hline \multirow{2}{*}{$\begin{array}{l}\text { Number of science classes in } \\
\text { high school }\end{array}$} & Three or more & 1 \\
\hline & Otherwise & 0 \\
\hline \multirow{2}{*}{ College level biology classes } & One or more & 1 \\
\hline & Otherwise & 0 \\
\hline \multirow[t]{2}{*}{ Major } & $\begin{array}{l}\text { Biology, microbiology, or pre- } \\
\text { med }\end{array}$ & 1 \\
\hline & Otherwise & 0 \\
\hline
\end{tabular}

Table 1. Binary classification used for the statistical analyses for the variables relating to students' demographics, preparedness, and major.

Volume Six $\mid$ 19 
a statistically significant higher proportion of younger (age 25 or below) and single (based on their marital status) students as compared to USCC. However, our results show no statistically significant difference in student composition in terms of gender, employment status, and nationality.

As shown in Fig. 1(B), in case of students' preparedness, a statistically significant higher proportion of $\mathrm{CU}$ students had completed three or more science classes during high school and had completed one or more college level biology classes before enrolling in microbiology class as compared to USCC students. Thus, the students at CU were academically better prepared to learn microbiology (or any science course) relative to students at USCC. Also, a statistically significant higher proportion of students at $\mathrm{CU}$ were biology, microbiology or pre-med majors relative to USCC.

Fig. 1 (C) summarizes the results with respect to students' interest in microbiology and their attitudes towards learning. Our results indicate no significant difference in students' interest in microbiology or their desire to be an active leader during laboratory exercises at both the institutions. However, it is interesting to note that students at USCC were statistically more interested in participating in classroom discussions and in learning course material outside the classroom relative to students at $\mathrm{CU}$.
Next, students' performance in pre-tests and posttests at USCC and CU was analyzed to assess if mean pre- and post-test scores in the four topics statistically

20| Fine Focus 


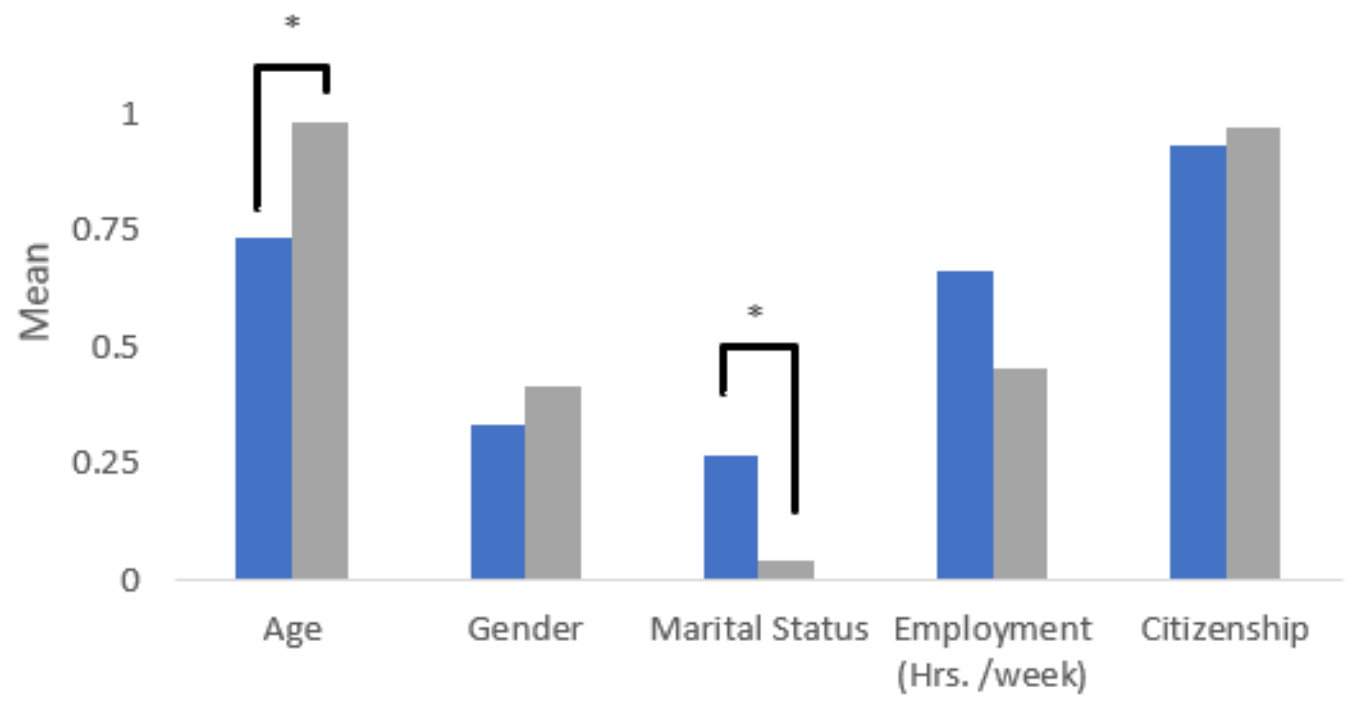

uSCC $\mathrm{CU}$

Figure 1A. Comparison of student demographics between USCC $(n=15)$ and CU $(n=70)$ based on a survey administered on first day of class. Binary classification of variables (age $=1$, if below 25 years; gender $=1$, if male; marital status $=1$, if married; employment $=1$, if hours worked $>10$ hours; citizenship $=1$, if domestic student and 0 otherwise) was used to test for equality of means between CU and USCC. Results show that age and marital status were statistically significantly different between the students at USCC and CU.

${ }^{*} p \leq 0.06$. 


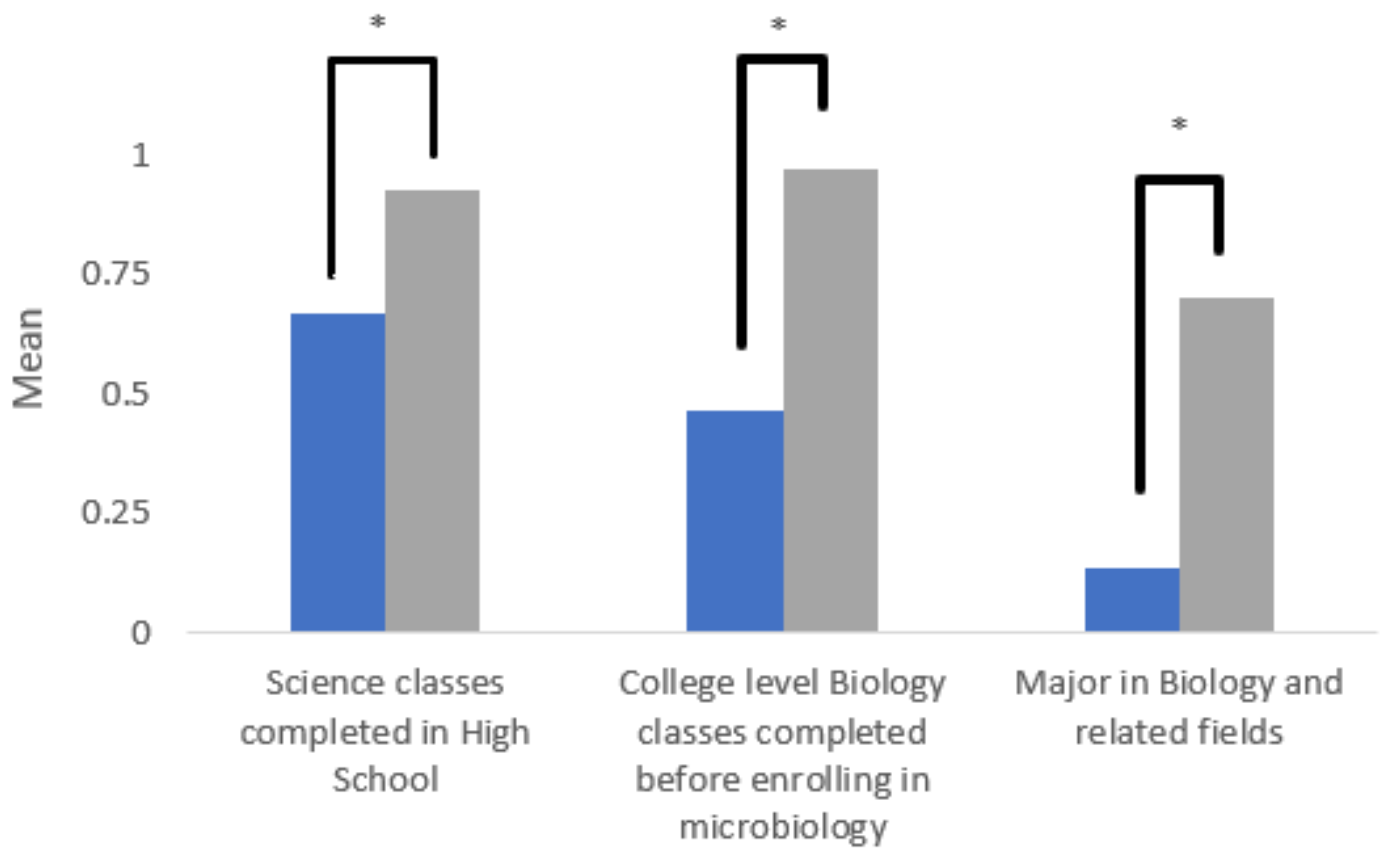

USCC $\mathrm{CU}$

Figure 1B. Comparison of student demographics between USCC $(n=15)$ and CU $(n=70)$ based on a survey administered on first day of class. Binary classification (number of science classes completed in high school $=1$, if 3 or more; college level biology classes completed before enrolling in microbiology = 1 , if 1 or more; major $=1$, if biology, microbiology, or pre-med, and 0 otherwise) was used to test for equality of means between CU and USCC. Results show that the number of science classes completed in high school, number of college level biology classes completed before enrolling in microbiology, and students' major were statistically significantly different between the students at USCC and CU.

${ }^{*} p \leq 0.06$.

$22 \mid$ Fine Focus 


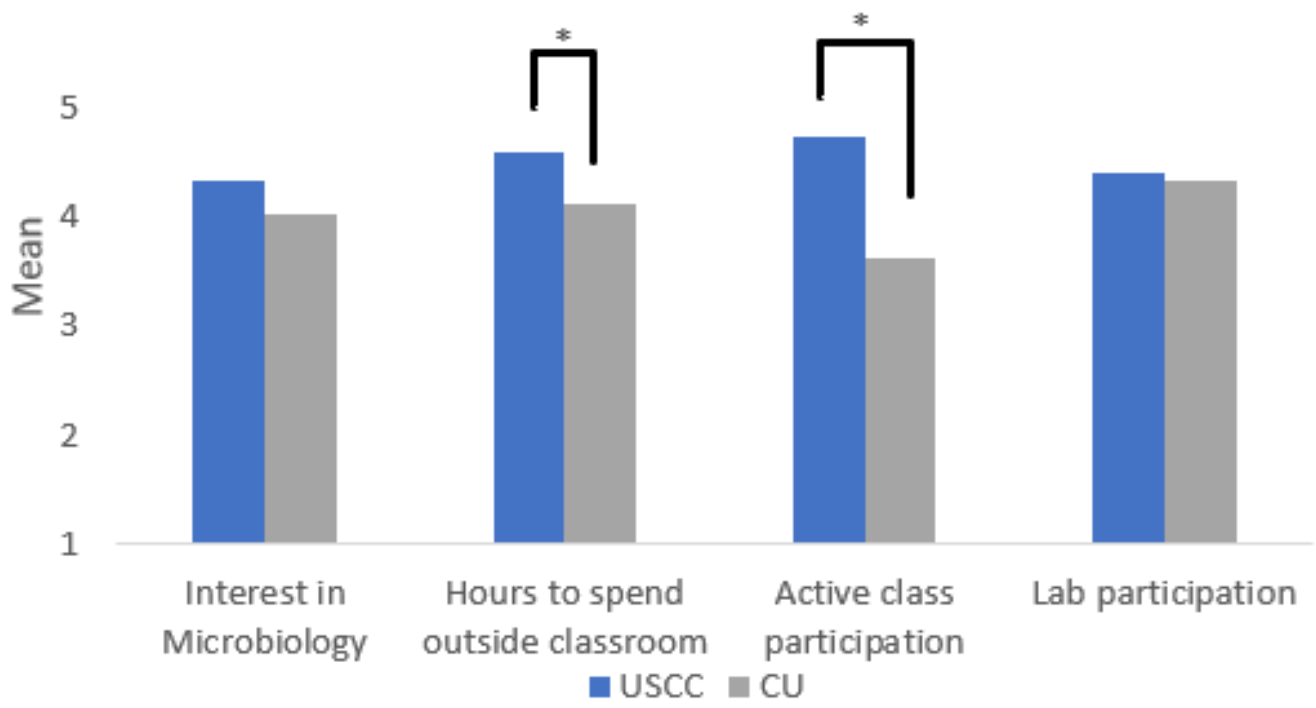

Figure 1C. Comparison of students' interest and attitudes towards learning microbiology between USCC $(n=15)$ and CU $(n=70)$ based on a survey administered on first day of class. A 5-point Likert scale was used to compare students' interest and other attitudes towards learning, with 1 representing least interest in microbiology and 5 representing high interest in microbiology; 1 representing less than 1 hour to spend outside the classroom and 5 representing over 5 hours to spend outside the classroom; 1 representing not likely to actively participate in the class and 5 representing very likely to actively participate in class; 1 representing do not care about lab participation and 5 representing taking the lead role in the lab group. Using test of equality of means, the figure show that hours devoted to learning outside the class and willingness for active class participation were statistically significantly higher amongst USCC students relative to CU students.

${ }^{*} p \leq 0.06$ 
vary between the students at two institutions. As shown in Fig. 2, our results indicate that the student scores in pre-tests for introduction, cell structure, microbial metabolism, and microbial growth were statistically significantly higher (at 6\% level) at CU relative to USCC, reflecting better prior knowledge about these topics at CU relative to USCC. However, the knowledge gap was closed as indicated by no statistically significant difference in students' mean scores in introduction and microbial metabolism posttests between the two institutions. In other two topics, cell structure and microbial growth, students at $\mathrm{CU}$ had a statistically significant higher post test scores as compared to USCC students.

We further analyzed and compared student performance in pre- and post-tests in different topics at both the institutions and the results are presented in Fig. 3. Our results show that classroom instruction led to significantly higher post-test scores (as compared to their pre-test scores) in all four topics at USCC and there was no significant statistical difference between pre-test and post-test scores in any of the four topics at CU. Thus, based on our analysis, after students were exposed to the topic in the classroom at USCC they had higher learning gains (as reflected by statistically significant higher post-test scores of USCC students in each of the four topics as compared to their pre-test scores).

To analyze learning gains between the students at USCC and CU, the difference in performance of each student before and after a topic was discussed was computed. The means of these differences were compared between the two institutions for each of the four topics. Our analysis shows that students at USCC exhibited statistically significant higher learning gains (at 6\% level of significance) in three out of four topics (introduction, cell structure, and microbial metabolism) (Fig. 4). At CU, the students did not exhibit learning gains in any of the four topics.

\section{Discussion \& Conclusions}

This research was conducted to fill the current gap in the literature regarding learning gains of students in a microbiology class at two different types of institutions, a two-year community college in the U.S. and a fouryear Canadian university, and their relationship to the demographics, preparedness, attitudes, study habits, and behavioral engagement towards learning. The results of this paper are based on (a) students' responses to a questionnaire on their demographics, preparedness for an introductory course in microbiology, major, and their attitudes and study habits towards learning; and (b) students' test scores in 4 different topics in microbiology, administered before and after the topic was taught in the classroom (pre- and posttests). Further, all students' responses were compared between 2-year college in the US and 4-year university in Canada.

Our research finds several interesting results: based on our sample results, statistically, students at CU were relatively younger and unmarried when compared to students at USCC. Statistically, students at USCC scored better grades in post-tests as compared to their pre-tests in all the topics. It may be mentioned that our 


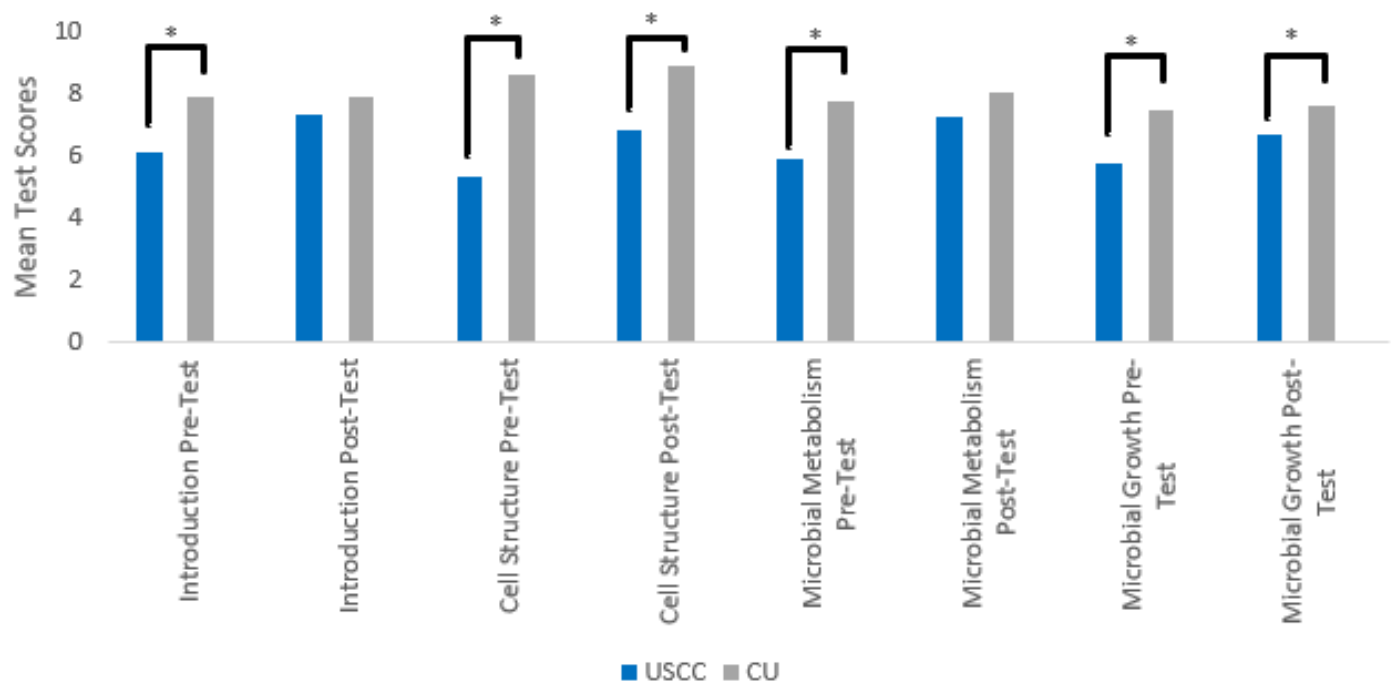

Figure 2. Comparison of mean performance of students in pre- and post-tests at USCC relative to CU. Results from the test of equality of means show that USCC students' mean scores were statistically significantly lower in all four pre-tests relative to CU students. However, performance of USCC students was statistically significantly lower in only 2 out of 4 post-tests (cell structure and microbial growth) relative to CU students. ${ }^{*} p \leq 0.06$ 


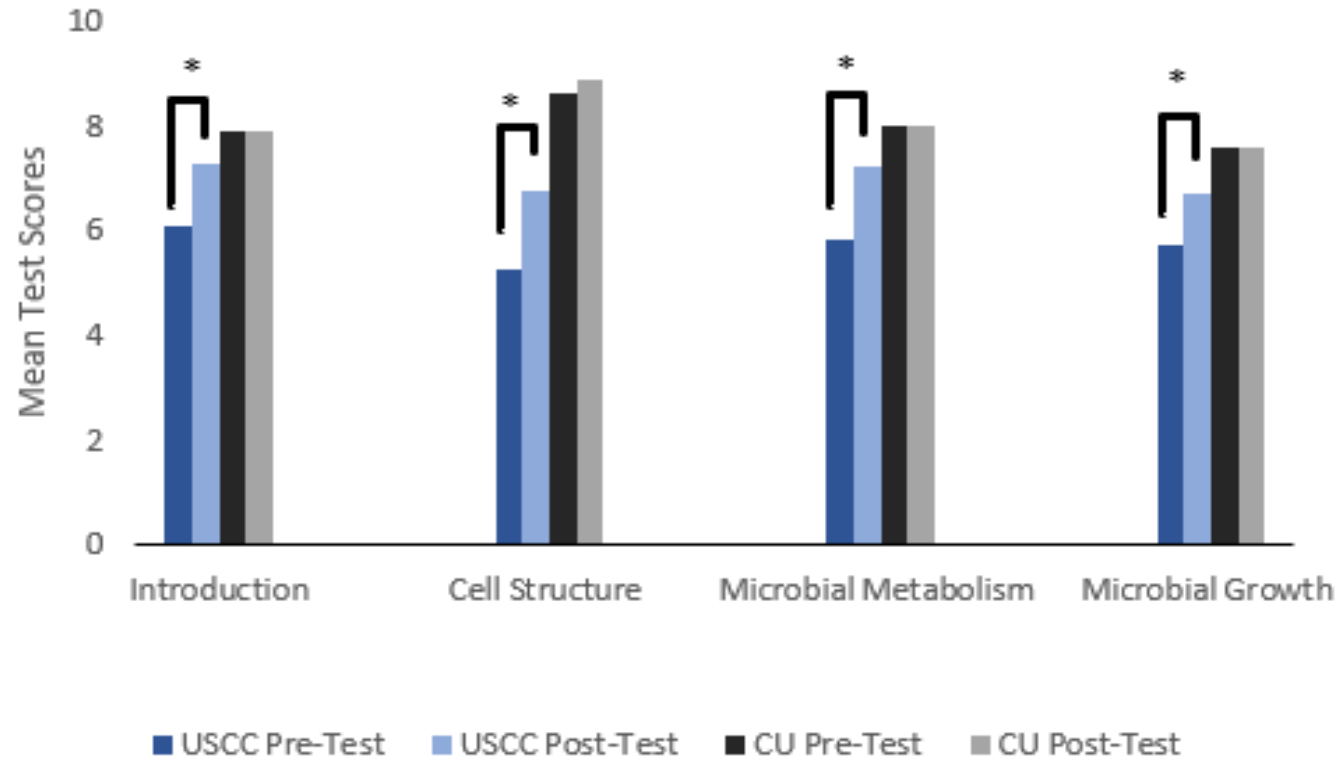

Figure 3. Comparison of means of the pre- and post-test scores of students at USCC and CU. Test of equality of means shows that students at USCC scored statistically significant higher scores in all 4 post-tests relative to pre-tests, reflecting higher learning gains after the topic was discussed in class. However, performance of students at CU was not statistically significantly different between pre- and post-tests in all four topics.

${ }^{*} p \leq 0.06$.

26| Fine Focus 


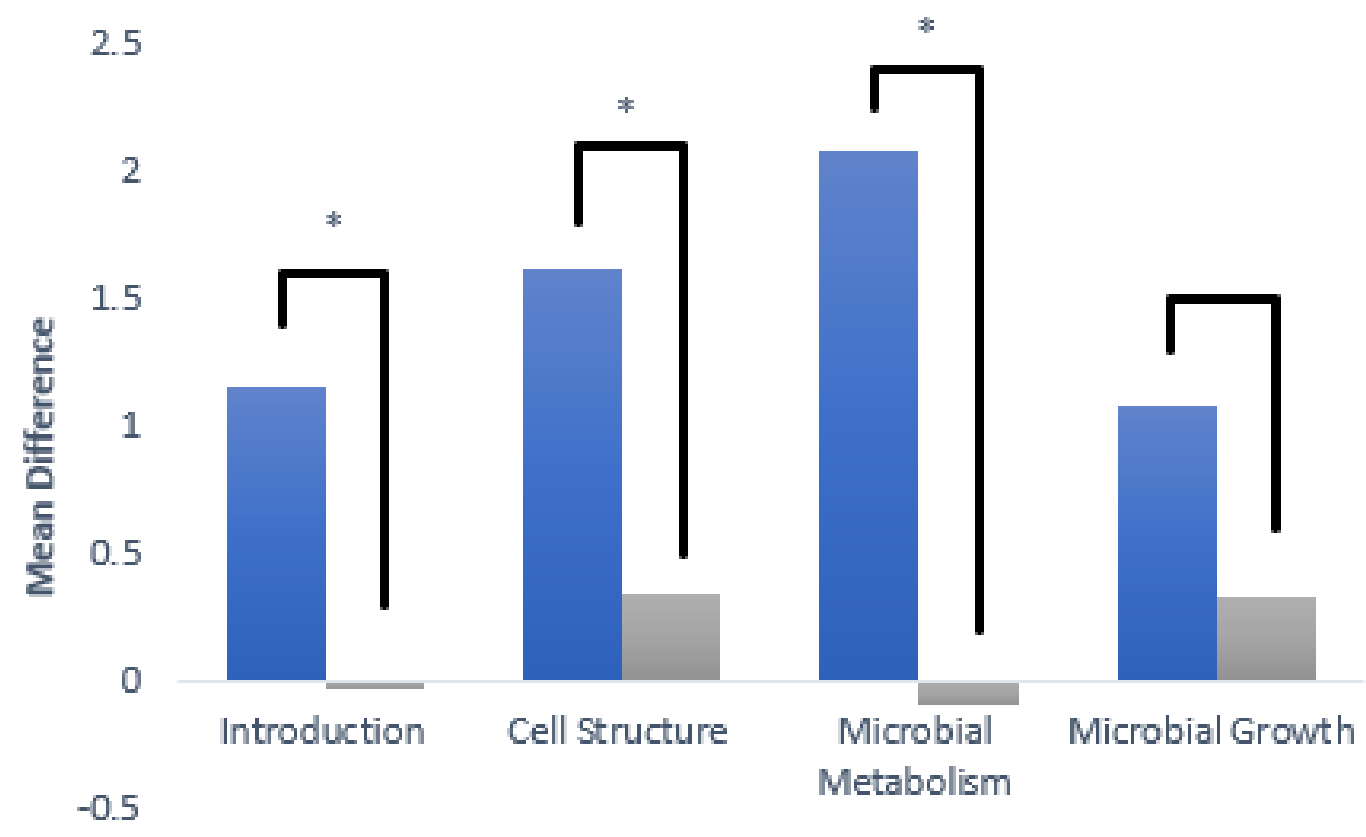

- USCC $\square \mathrm{CU}$

Figure 4. Difference of means between the post-test vs pre-test scores at USCC and CU. Test of equality of means shows that there was a statistically significant difference between the post-test versus pre-test scores amongst USCC students relative to CU students in 3 out of 4 topics (introduction, cell structure, and microbial metabolism).

${ }^{*} p \leq 0.06$. 
results reflect correlations between these variables rather than causality. However, it is interesting to note that Richardson and King concluded that older students tend to exhibit more desirable approaches to learning in terms of both their persistence and attainment (21). Newman-Ford et.al also reported that despite attaining lower results overall, older students achieve a higher proportion of better grades and age had some impact upon educational achievement (20). Our results show no statistical difference between CU and USCC with respect to other three demographic factors, gender, citizenship, and number of students working 10 hours or more per week.

We found that statistically CU students were academically better prepared for introductory microbiology class relative to students at USCC, when preparedness is measured in terms of number of science courses completed during high school and their prior exposure to college level biology classes. A statistically higher proportion of CU students were biology/microbiology majors and had more exposure to science courses in high school and first year of college before taking microbiology class. Our results show that students at $\mathrm{CU}$ had statistically significant higher pre-test scores as compared to students at USCC in all four topics studied. Despite this, students at USCC scored statistically significant higher grades in all the post-tests as compared to their pre-tests. These results are contradictory to Newman-Ford et al. who found a strong, statistically significant relationship between prior attainment and subsequent results (20). Our results are consistent with Mlambo who also reported that entry qualifications do not significantly affect academic performance in an introductory 28 | Fine Focus biochemistry class (19). Colorado and Eberle also reported that academic performance in online learning environments was not significantly affected by the number of educational degrees attained (16).

We also found that students at USCC were willing to devote more time outside the classroom to study and to actively participate in class to learn microbiology when compared to students at CU. Our results show that students at USCC attained significantly higher posttest scores as compared to their pre-test scores. These results are consistent with the result of a study by Harb and El-Shaarawi that students who participate in class discussion outperform students who do not (22).

We then compared students' scores on post-test with students' scores on pre-test at each of the two institutions separately. Interestingly, we found that the post- test scores of students in all four topics were statistically significantly higher from their pre-test scores at USCC. No such statistical difference between students' performance on pre- and post-tests in the case of CU students was found. It is evident from the questionnaire data that students at USCC were not as well prepared to handle the rigor of college microbiology class (as evident from their lower scores in pre-tests, number of science classes completed at high school, and number of biology courses completed at college before enrolling in microbiology). But after exposure to the topic in the class they achieved statistically higher learning gains as compared to the students at CU. A study by Yager et al. showed that students with or without prior high school science work exhibited similar performance on all assessments after course completion simply because 
students without high school science program worked extra hard and devoted more time to learning (25).

An interesting question is why students' scores were consistently higher on post-test relative to pre-test in case of USCC and not so in the case of CU. There could be several explanations for this.

The class size was much larger at $\mathrm{CU}$ relative to USCC. Though the same lecture-discussion format was used to discuss a topic in the classroom and both the instructors tried to use the class and lab time in a similar manner, due to the smaller class size at USCC, students might have had the advantage of getting more interaction with the instructor and among themselves as compared to the 4-year university where the class size was big. Though, at both the institutions, instructors maintained regular office hours to interact individually with the students and involve them in one-on-one discussion, the students at CU who were mostly biology/microbiology majors with heavier course load and more exposure to college level courses may not have utilized that opportunity.

Based on students' responses, our results indicate that students at $\mathrm{CU}$ were better prepared to learn microbiology, as statistically a higher proportion of them had completed three or more science classes during high school and were also exposed to college level biology courses. It is also evident from their significantly higher pre-test scores in all the topics. Despite the lower pre-test scores of USCC students, statistically they were more willing to spend more time outside the classroom to study and actively participate in the classroom to learn when compared to $\mathrm{CU}$ students and it is evident from their higher learning gains.

Statistically, at USCC, students were older and married and hence, may be more responsible and committed to learning as compared to more traditional students at CU. As reported by Newman-Ford et al. despite attaining lower results overall, older students achieve a higher proportion of better grades and age had some impact upon educational achievement (20). Richardson and King also concluded that older students tend to exhibit more desirable approaches to learning in terms of both their persistence and attainment (21).

It must be acknowledged that though students at $\mathrm{CU}$ did not have any statistically significant learning gains in any of the four topics in microbiology, they still had higher overall scores on the post tests. However, performance of USCC students was statistically significantly lower in only 2 out of 4 post-tests (cell structure and microbial growth) relative to $\mathrm{CU}$ students.

In conclusion, our results indicate that if students are willing to spend time to learn, and have the right attitudes towards learning, they can overcome their prior deficiencies and achieve higher learning gains.

This study, though preliminary and exploratory, has created a space for the further investigation of learning gains of major and non-major students in a microbiology class at two different types of institutions with different student demographic. It serves as a 
starting point of research in such an area.

\section{Research Challenges}

This research has few limitations. First, it is limited by the differences in class size at the two institutions. CU had a significantly larger class size as compared to USCC. Second, though every effort was made to follow the same type of lecture-discussion format in both the classrooms and both instructors were in frequent communication via phones and email messages about the instructions and worked closely together throughout the project, the individual instructor differences might have caused some differences observed in the results. Third, at USCC, students could enroll in microbiology as freshmen and the course has no prerequisite, whereas at $\mathrm{CU}$ it is a sophomore level class with a year of biology and chemistry as prerequisites and, hence, students at CU were academically better prepared for the class.

\section{Suggestions for Future Research}

This research was done at one 2-year community college and one 4-year university for one semester. It will be interesting and useful to expand it to include more 2-year and 4-year institutions in the U.S. and Canada to increase the sample size and conduct additional statistical investigation to further explain the differences in students' learning gains at different institutions.

\section{Acknowledgements}

The authors are grateful to Dr. Anil K. Lal, Professor of Economics for his numerous suggestions during statistical analysis of the data.
The authors are also grateful to the American Society for Microbiology's Biology Scholars 2016 Writing and Publishing Course, From Science Education Research to Publication Workshop, and would like to thank the course cohort, Dr. Marcy Kelly, the course instructor, and other mentors for the meaningful discussions and their feedback during the writing phase of this manuscript. Our thanks go to Drs. Karen Densky and Catharine Dishke Hondzel and Kara Loy of the Centre for Excellence in Learning and Teaching, Brenda Smith and Shane Neifer of Library, Gabrielle Kam and Chadabhorn Insuk of Faculty of Science, for their assistance.

The authors declare that there are no conflicts of interest.

30| Fine Focus 


\section{References}

1. The Government of Canada. (2018). The Government of Canada and STEM: Retrieved from https:// www.ic.gc.ca/eic/site/013.nsf/eng/00014.html

2. DeCoito, I., Steele, A., \& Goodnough, K. (2016) Introduction to the Special Issue on Science, Technology, Engineering, and Mathematics (STEM) Education. Canadian Journal of Science, Mathematics and Technology Education, 16(2), 109-113. DOI: 10.1080/14926156.2016.1166298

3. The Conference Board of Canada. (2013). Percentage of Graduates in Science, Math, Computer Science, and Engineering. Retrieved from: https://www.conferenceboard.ca/hcp/Details/education/ graduates-science-math-computer-science-engineerin.aspx

4. The Conference Board of Canada. (2014). Shortfalls in Key Skills Prompt Need for Improvements in Post-Secondary Education Sector. Retrieved from: https://www.conferenceboard.ca/press/ newsrelease/14 104/Shortfalls_in_Key_Skills_Prompt_Need_for_Improvements_in_Post_Secondary_ Education_Sector.aspx?AspxAutoDetectCookieSupport=1

5. Blotnicky, K. A., Franz-Odendaal, T., French, F., \& Joy, P. (2018). A study of the correlation between STEM career knowledge, mathematics self-efficacy, career interests, and career activities on the likelihood of pursuing a STEM career among middle school students. International Journal of STEM education, 5(1), 22. DOI:10.1186/s40594-018-0118-3

6. Cavanagh, C., Crapper, L., Dietrich, K., Gruosso, T., Gaultieri, C., Huang, Y-S., Lien, P., Kropf, P., McGuirk, S., Phan, K. \& Sung, V. (2016). Student perspective of STEM education in Canada: Strategies and solutions from an expert-led working group. Retrieved from: http://sp-exchange.ca/images/reports/ Student\%20perspective\%20of\%20STEM\%20education\%20in\%20Canada\%2C\%20SPE\%20white\%20 paper.pdf

7. Toulmin, C., \& Groome, M. (2007). Building a Science, Technology, Engineering, and Math Agenda. 
National Governor's Association, Washington, DC.

8. AERA. (2012). PCAST report recommends action to increase number of STEM graduates. Retrieved from http://www.aera.net/Newsroom/AERA-Highlights-E-newsletter/AERA-Highlights-ArchivalIssues/AERA-Highlights-February-2012/PCAST-Report-Recommends-Action-to-Increase-Number

9. National Math and Science Initiative (NMSI). n.d. The Stem Crisis: STEM Education Statistics. Retrieved from https://www.nms.org/AboutNMSI/TheSTEMCrisis/STEMEducationStatistics.aspx

10. National Science \& Technology Council (December 2018) Charting a course for success: America’s strategy for STEM education. Retrieved Jan 14, 2020 https://www.whitehouse.gov/wp-content/ uploads/2018/12/STEM-Education-Strategic-Plan-2018.pdf

11. Astin, A., \& Astin, H. (1992). Undergraduate science education: The impact of different college environments and the educational pipeline in colleges. Final Report. ED 362, 404.

12. Leppel, K. (2002). Similarities and differences in the college persistence of men and women. The Review of Higher Education, 25(4), 433-450. DOI:10.1353/rhe.2002.0021

13. Cabrera, A. F., \& La Nasa, S. M. (2002). Overcoming the tasks on the path to college for America's disadvantaged. New Directions for Institutional Research, 2000(107), 31-43. DOI:10.1002/ir.10703

14. Whalen, D. F., \& Shelley II, M. C. (2010). Academic success for STEM and non-STEM majors. Journal of STEM Education, $11(1 \& 2)$, 45-60.

15. Olenchek, F. R., \& Hebert, T. P. (2002). Endangered academic talent: Lessons learned from gifted firstgeneration college males. Journal of College Student Development, 43(2), 195-212.

16. Colorado, J. T., \& Eberle, J. (2010). Student demographics and success in online learning environments. Emporia State Research Studies, 46(1), 4-10.

17. Jayanthi, S. V., Balakrishnan, S., Ching, A. L. S., Latiff, N. A. A., \& Nasirudeen, A. M. A. (2014). 
Factors Contributing to Academic Performance of Students in a Tertiary Institution in Singapore. American Journal of Educational Research, 2(9), 752-758. DOI:10.12691/education-2-9-8

18. Lal, A. K., \& Cortes, B. S. (2008). An analysis of attitudes towards foreign trade. Journal of Economics and Economic Education Research, 9(3), 101-115.

19. Mlambo, V. (2011). An analysis of some factors affecting student academic performance in an introductory biochemistry course at the University of West Indies. Caribbean Teaching Scholar, 1(2), 79-92.

20. Newman-Ford, L., Lloyd L., \& Thomas, S. (2009). An investigation in the effects of gender, prior academic achievement, place of residence, age and attendance on first-year undergraduate attainment. Journal of Applied Research in Higher Education, 1(1), 13-28. DOI:10.1108/17581184200800002

21. Richardson, J. T. E., \& King, E. (1998). Adult Students in Higher Education: Burden or Boon. Journal of Higher Education, 69, 65-88.

22. Harb, N., \& El-Shaarawi, A. (2007). Factors affecting students' performance. Journal of Business Education, 82(5), 282-290

23. Tahir, I. M., \& Abu Baker, N. M. (2009). Influence of demographic factors on students' beliefs in learning mathematics. International Education Studies, 2(3), 120-126.

24. Tai, R.H., Sadler, P. M., \& Loehr, J. F. (2005). Factors influencing success in Introductory College Chemistry. Journal of Research in Science Teaching, 42(9), 987-1012. DOI: 10.1002/tea.20082

25. Yager, R. E., Snider B., \& Krajcik, J. (1988). Relative success in college chemistry for students who experienced a high school course in chemistry and those who had not. Journal of Research in Science Teaching, 25(5), 387-396. DOI:10.1002/tea.3660250506 
Erratum: Author information has been updated as follows.

Archana Lal ${ }^{1} \&$ Naowarat Cheeptham ${ }^{2}$

${ }^{1}$ Corresponding author; Labette Community College, Parsons, KS 67357,

USA email: ArchanaL@labette.edu

${ }^{2}$ Department of Biological Sciences, Thompson Rivers University, Kamloops, B.C., Canada 